\title{
ANALISIS PENGARUH VARIASI WAKTU SINTERING DAN KOMPOSISI TERHADAP SIFAT MEKANIK DAN MORFOLOGI KOMPOSIT ECENG GONDOK-PVC-LDPE
}

\author{
Novi Laura Indrayani ${ }^{*}$, R Hengki Rahmanto, Riri Sadiana \\ Program Studi Teknik Mesin, Fakultas Teknik, Universitas Islam 45 \\ Jl. Cut Meutia No. 83 Mergahayu Bekasi Timur Kota Bekasi-Jawa Barat 17113. \\ *Email: novie.laura@gmail.com
}

\begin{abstract}
Abstrak
"Pemanfaatan material komposit pada saat ini semakin berkembang, seiring dengan meningkatnya penggunaan bahan tersebut yang semakin meluas mulai dari yang sederhana sampai sektor industri. Hal ini dikarenakan karakteristik material komposit mempunyai banyak kelebihan dibandingkan dengan jenis bahan lain yaitu ringan, kuat, tidak terpengaruh korosi dan mampu bersaing dengan logam, dengan tidak kehilangan karakteristik dan kekuatan mekanisnya. Penelitian ini bertujuan untuk mengetahui pengaruh variasi waktu sintering dan komposisi terhadap ketangguhan impak dan kekerasan komposit Eceng GondokPVC-LDPE. Bahan yang digunakan merupakan tanaman gulma dan limbah plastik. Proses pembuatan spesimen dilakukan dengan metode pressured sintering, yaitu dengan cara pembuatan serbuk, dan di screening 60 mesh. Selanjutnya serbuk di mixing dengan variasi komposisi perbandingan K1: EG 50\%, PVC 10\%, LDPE 40\%; K2: EG 55\%, PVC 10\%, LDPE 35\%; K3: EG 60\%, PVC 10\%, LDPE 30\%; K4: EG 65\%, PVC 10\%, LDPE 25\% dan K5: EG 70\%, PVC 10\%, LDPE 20\% dan dikompaksi dengan tekanan 1,013 bar. Selanjutnya di sintering dengan temperatur $180^{\circ} \mathrm{C}$. Pada penilitian ini variasi waktu sintering yaitu; 5 menit, 8 menit, 10 menit, 13 menit dan 15 menit. Sifat mekanik dilihat dari nilai kekerasan dan impak dengan menggunakan standar ISO 2039-1:2001, ISO 179-1:2010. Selain itu menganalisis morfologi dengan Scanning Electron Microscope (SEM). Pengujian untuk sifat kimia dilihat dengan analisis morfologi SEM. Berdasarkan hasil pengujian sifat mekanik didapatkan nilai kekerasan tertinggi dimiliki oleh komposit K2 sebesar $22.30 \mathrm{MPa}$ dan $2.1 \mathrm{~kJ} / \mathrm{m}^{2}$ untuk nilai impak."
\end{abstract}

Kata kunci: eceng gondok, komposit, LDPE, pressured sintering, PVC.

\begin{abstract}
"The utilization of composite materials nowadays is currently growing, along with the increasing use of these materials, which are expanding ranging from the small scale to the industrial sector. This is because the characteristics of composite materials have many advantages compared to other types of materials i.e. light, strong, not affected by corrosion and able to compete with metals without losing their mechanical characteristics and strength. This research aims to determine the effect of variations in sintering time and it's composition against impact toughness and hardness of the Water Hyacinth-PVC-LDPE composite. The materials used are weeds and plastic waste. The process of specimen fabrication was performed by using pressured sintering method, i.e. by making it into powder and were screening by using screen 60 mesh. Furthermore, the powder were mixed with the variation of the composition K1: EG 50\%, PVC 10\%, LDPE 40\%; K2: EG 55\%, PVC 10\%, LDPE 35\%; K3: EG 60\%, PVC 10\%, LDPE 30\%; K4: EG 65\%, PVC 10\%, LDPE 25\% dan K5: EG 70\%, PVC 10\%, LDPE 20\% and compacted with a pressure of 1,1013 bar. After that is sintering with temperature $180^{\circ} \mathrm{C}$. In this research the sintering time variations is 5 minute, 8 minute, 10 minute, 13 minute and 15 minute. Mechanical properties if were seen from the hardness and impact values by using a standard ISO 2039-1:2001, ISO 179-1:2010. In additions to analyze the morphology by using a Scanning Electron Microscope (SEM). Tests for chemical properties can be seen with the morphological analysis of SEM. Based on the testing results, the mechanical properties obtained the highest hardness value owned by a composite K2 by 22.30 MPa and $2.1 \mathrm{~kJ} / \mathrm{m}^{2}$ for the value of the impact."
\end{abstract}

Kata kunci:water hyacinth, composite, LDPE, pressured sintering, PVC. 


\section{PENDAHULUAN}

Kebutuhan manufaktur di era teknologi seperti saat ini mulai mengalami pergeseran. Misalnya, tuntutan menghasilkan mobil atau pesawat berbobot ringan. Dikarenakan pemakaian logam yang terus meningkat membuat ketersedian logam semakin menipis di alam, untuk itu dibutuhkan sebuah material alternatif yang bisa mewakili sifat-sifat dari logam tersebut. Hal ini mendorong produsen mencari material baru yang lebih ringan dari logam, tapi memiliki sifat mekanik yang sama baiknya. Maka muncul material komposit sebagai material alternatif karena bobotnya yang sangat ringan tapi superkuat. Salah satu jenis komposit adalah komposit daur ulang yang menggunakan bahan dasar sampah organik dan anorganik (Karso, 2012).

Sustainable Waste Indonesia (SWI) 2018 mengungkapkan sebanyak $24 \%$ atau sekitar 65 juta ton sampah di Indonesia masih tidak terkelola dengan baik. Dan, sekitar 15 juta ton mengotori ekosistem juga lingkungan karena tidak ditangani dengan baik. Hanya 7\% sampah didaur ulang dan 69\% sampah berakhir di Tempat Pembuangan Akhir (TPA). Dari laporan tersebut diketahui jenis sampah yang paling banyak dihasilkan adalah sampah organik sebanyak $60 \%$, sampah plastik $14 \%$, diikuti sampah kertas 9\%, metal 4,3\%, kaca, kayu dan bahan lainya 12,7\% (Indrayani, 2019).

Selain itu, pertumbuhan eceng gondok yang cepat dan tak terkendali dapat merusak lingkungan perairan sehingga eceng gondok lebih dikenal sebagai tanaman gulma. Namun serat eceng gondok merupakan salah satu material natural fiber alternatif dalam pembuatan komposit. Secara ilmiah pemanfaatan masih dikembangkan, karena belum ditemukan material komposit yang menggunakan serat eceng gondok. Serat eceng gondok lebih banyak digunakan dalam industri kecil menengah dan kerajinan rumah tangga. Oleh karena itu, pengembangan pembuatan komposit daur ulang berbahan dasar sampah merupakan salah satu alternatif untuk menjadi material baru layak guna (Hadi, 2012).

Hameed dkk, menyebutkan sampah plastik PET dapat digunakan sebagai perekat komposit untuk industri konstruksi. Komposit dibuat dengan PET sebagai filler dan beton sebagai matriks, dengan variasi PET 1\%, 3\%, 5\%, 7\% dan $10 \%$, didapatkan semakin besar variasinya semakin baik nilai impaknya. Seghiri dkk (2017), melakukan hal yang sama yaitu membuat komposit matrik polimer dari sampah plastik HDPE sebagai produk genteng. Melihat pengaruh komposit polimer HDPE dengan variasi komposisi HDPE 30\%, 40\%, 50\%, 60\%, $70 \%$ dan $80 \%$ terhadap nilai impak dan kekerasan.

Jiang dkk (2020, membuat komposit bambu plastik (BPC) dengan mencampurkan bambu dengan resin yang berasal dari campuran plastik PE, PP dan PVC. Pada penlitian ini dilihat profil biodegradasi material biokomposit BPC. Sorini dkk (2020), melaporkan pada penelitiannya bahwa pembuatan komposit matrik polimer membutuhkan energi yang besar, sehingga waktu, suhu dan tekanan menjadi faktor utama serat karbon merekat baik pada komposit matrik polimer. Hasil kekuatan impak dan nilai kekerasan dipengaruhi proses panas yang dilakukan untuk pembuatannya. Setiajit dkk (2016), pada penelitiannya menyebutkan bahwa pengaruh waktu penekanan mempengaruhi sifat mekanik komposit matrik polimer yang dihasilkan. Komposit jenis ini lebih baik dibuat dengan metode hot press, karena komposit tidak akan mengalami degradasi. Waktu penekanan divariasikan menjadi 5, 10, 15, 20 dan 25 menit, didapatkan bahwa nilai impak waktu penekanan terbaik ada pada 5 menit.

Berdasarkan pertimbangan-pertimbangan tersebut maka penelitian ini dilakukan untuk mendapatkan karakteristik sifat mekanis dan fisis berupa kekuatan impak dan kekerasan dari komposit serat eceng gondok dengan matrik plastik PVC dan LDPE. Metode teknologi serbuk menjadi salah satu alternatif untuk membuat paduan atau komposit matrik polimer ini. Teknologi ini telah lama digunakan untuk membentuk produk dengan ukuran kecil dan berasal dari bahan yang sulit diproses melalui pemesinan, teknologi ini mempersyaratkan bahan dasar berupa serbuk dengan melalui tahap: pencampuran, kompaksi dan sintering. Keuntungan teknik kompaksi untuk material plastik adalah mampu mempertahankan bentuk produk sesuai cetakan. Dengan kata lain, pressured sintering tidak menyebabkan distrosi dimensi (German, 1994; Indrayani, 2019).

Faktor-faktor yang mempengaruhi kekuatan bahan yang terbuat dari teknologi serbuk antara lain adalah: ukuran partikel serbuk, besarnya tekanan, temperatur sintering, lamanya waktu penahanan sintering, volume zat pengikat (Rohmad dkk, 2013; Indrayani, 2019). Lamanya waktu sintering akan menentukan kuatnya ikatan antar partikel. Namun demikian akan terdapat waktu sintering yang optimal dalam pembentukan ikatan komposit matriks polimer. Metode yang 
dilakukan adalah sintering dengan melihat pengaruh waktu dan komposisi.

\section{METODOLOGI}

Penelitian dilakukan di 3 tempat yaitu di Workshop Teknik Mesin Unisma Bekasi, pengujian material di Sentra Teknologi Polimer-BPPT, dan pengujian morfologi di Laboratorium SEM Teknologi Polimer-BPPT. Prosedur penelitian dimulai dari pemilihan bahan baku, proses pembuatan bahan menjadi serbuk, proses screening, proses mixing, proses pencetakan dan kompaksi, proses sintering, dan proses pengujian.

\subsection{Bahan dan Alat Penelitian}

Bahan yang digunakan dalam penelitian ini adalah Eceng gondok (EG), sampah plastik PVC dan LDPE. Ketiga bahan dibuat menjadi serbuk. Proses pembuatan serbuk, proses mixing dan proses kompaksi serbuk dilakukan di workshop. Sedangkan alat-alat yang digunakan sebagai berikut: gerinda manual, catter, kuas, sarung tangan, infrared thermometer, mixer listrik, cetakan, mesin press, jangka sorong.

\subsection{Prosedur Penelitian}

Prosedur penelitian dibagi menjadi 5 tahapan dan proses pengujian berupa uji impak, uji kekerasan dan analisis morfologi. Proses awal adalah proses pembuatan bahan eceng gondok, sampah plastik PVC dan LDPE menjadi serbuk. Serbuk didapatkan dengan metode gerus (attrition) yaitu penggerindaan yang kemudian di screening sampai mencapai ukuran sekitar 60 mesh, seperti terlihat pada Gambar 1. Proses screening dilakukan untuk memisahkan ukuran material agar material serbuk bisa seragam dalam ukuran dan untuk menghindari terjadinya rongga-rongga karena perbedaan ukuran dalam proses kompaksi, screening juga bermanfaat untuk menyaring kotoran yang terjadi saat proses penggerindaan material.

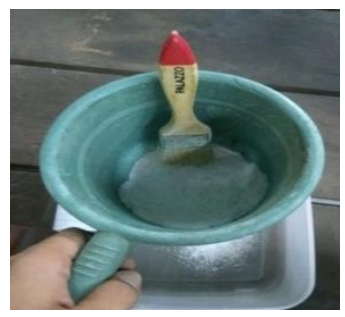

(a)

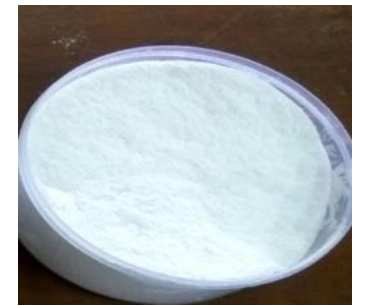

(b)
Gambar 1. (a) Proses Screening (b) Serbuk Matrik

Proses selanjutnya adalah mixing, proses ini dilakukan agar mendapatkan material serbuk yang homogen. Proses mixing dilakukan dengan mesin bubut, proses ini dilakukan untuk mendapatkan material serbuk yang homogen (Gambar 2). Proses persentasi campuran dilakukan dengan cara mengukur dari panjang dengan lebar cetakan. Agar proses mixing persisi harus menggunakan penggaris dan pembatas yang kuat. Komposisi yang akan dibuat untuk material komposit adalah K1: EG 50\%, PVC 10\%, LDPE 40\%; K2: EG 55\%, PVC 10\%, LDPE 35\%; K3: EG 60\%, PVC $10 \%$, LDPE 30\%; K4: EG 65\%, PVC 10\%, LDPE 25\% dan K5: EG 70\%, PVC 10\%.

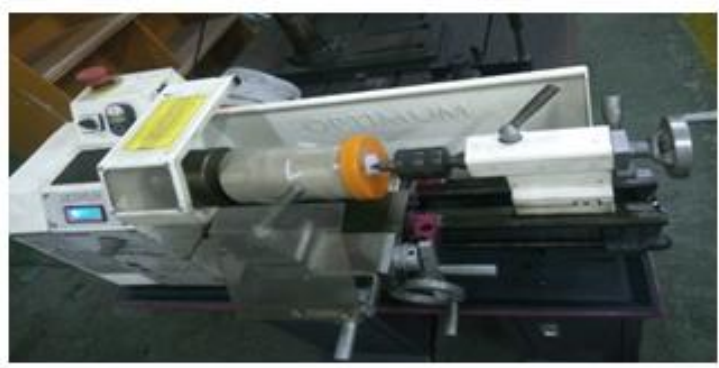

Gambar 2. Proses Mixing

Proses pencetakan dan kompokasi dilakukan setelah proses mixing, cetakan yang digunakan untuk mengkompaksi campuran serbuk terbuat dari baja, dimana material ini sangat kuat untuk menahan tekanan tinggi dari mesin pengepress. Setelah dikompaksi spesimen diambil dengan mendorong upper punch keluar cetakan. Proses hot compaction dilakukan bersamaan dengan proses sintering dengan mesin hot press seperti yang ditunjukkan pada Gambar 3. Pada penelitian ini tidak digunakan bahan pengikat, hal ini karena diinginkan pengikatan serbuk hanya terjadi sebagai efek dari sintering. Proses sintering merupakan proses pemanasan serbuk dengan elemen pemanas yang ditempatkan pada punch dan dies. Temperatur dalam dies diatur $180^{\circ} \mathrm{C}$, tekanan 0,2 bar, dengan memvariasikan holding time yaitu 5, 8, 10, 13 dan 15 menit. Pendinginan setelah sintering dilakukan dengan mengeluarkan spesimen dari dies dan membiarkannya di udara bebas.

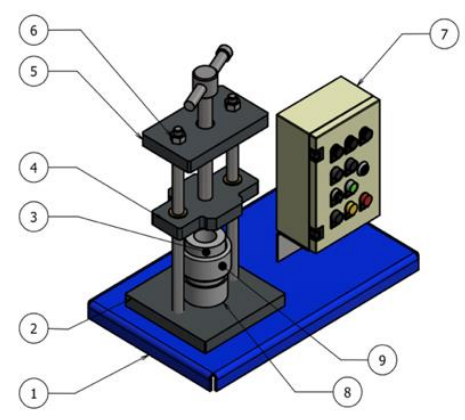

Gambar 3. Mesin Hot Press 
Keterangan:

1. Frame

2. Lower Guide

3. Dies

4. Sliding Guide

5. Upper Guide

6. Guide Bar

7. Panel Control

8. Guide Table

9. Coil Heater

Pengujian Material; Karakteristik sifat mekanik yang dilakukan untuk mengetahui karakter material adalah uji kekerasan dan uji impak. Pengujian kekerasan menggunakan metode Hardness Ball Indentation berdasarkan standar ISO 2039-1:2001 atau ASTM D-1037. Spesimen uji memiliki dimensi T: (4) $\mathrm{mm}, \mathrm{L}$ : (50) $\mathrm{mm}$, P: (50) mm. Sedangkan pengujian impak menggunakan metode charpy yang berdasarkan standar ISO 179:2010 atau ASTM D-5941. Dimensi pengujian adalah T: $4 \mathrm{~mm}$, L: $10 \mathrm{~mm}$ dan P : 80. Pengujian morfologi pada spesimen uji bertujuan untuk mengamati apa yang terjadi di dalam spesimen antara matriks dan filler menggunakan alat EOL-JSM6510LA. Dimensi spesimen uji T: (3) mm, L: (30) $\mathrm{mm}, \quad \mathrm{P}:$ (30) $\mathrm{mm}$, dengan variasi pembesaran 5X hingga 300000X.

\section{HASIL DAN PEMBAHASAN}

Pada bahan komposit, sifat-sifat unsur pembentuknya masih terlihat jelas. Keunggulan bahan komposit adalah penggabungan sifatsifat unggul masing-masing unsur pembentuknya yaitu Eceng gondok (EG), LDPE, PVC. Bahan komposit pada penelitian ini dibentuk dari dua unsur, yaitu filler (serat) dan bahan pengikat serat-serat tersebut yang disebut matriks. Komposit EG-PVC-LDPE tersusun dari dua jenis matriks yaitu, plastik LDPE dan plastik PVC dengan satu filler yaitu Eceng gondok. Filler yang nantinya menentukan karakteristik bahan komposit EGPVC-LDPE, seperti: kekakuan, kekuatan serta sifat-sifat mekanik yang lain. Pada penelitian ini akan dilihat pengaruh komposisi filler dan matriks bahan komposit EG-PVC-LDPE dan waktu penahanan sintering terhadap nilai kekerasan. Selain itu juga akan dilihat dari bentuk morfologinya.

\subsection{Pengaruh Komposisi dan Waktu Terhadap Nilai Kekerasan}

Nilai kekerasan komposit EG-PVC-LDPE dilihat dengan melakukan pengujian Hardness Ball Indentation menggunakan alat uji EMCO TEST dan menggunakan standar ISO 20391:2001. Menurut standar, dimensi yang digunakan adalah: T: $4 \mathrm{~mm}, \mathrm{~L}: 50 \mathrm{~mm}, \mathrm{P}: 50$ $\mathrm{mm}$. Pengaruh komposisi dan waktu sintering terhadap Hardness Ball Indentation disajikan melalui data percobaan yang ditunjukan pada Tabel 1 dan Gambar 4.

Tabel 1. Data Hasil Pengujian Kekerasan Komposit EG-PVC-LDPE

\begin{tabular}{cccccc}
\hline \multirow{2}{*}{$\begin{array}{c}\text { Nama } \\
\text { Sampel }\end{array}$} & \multicolumn{5}{c}{$\begin{array}{c}\text { Hardness Ball Indentation } \\
\text { (MPa) }\end{array}$} \\
\cline { 2 - 6 } K1 & $\mathbf{5 ~ s e c}$ & $\mathbf{8 ~ \mathbf { ~ s e c }}$ & $\mathbf{1 0 ~ \mathbf { ~ s e c }}$ & $\mathbf{1 3} \mathbf{~ s e c}$ & $\mathbf{1 5} \mathbf{~ s e c}$ \\
K2 & 20,00 & 19,90 & 21,40 & 16,60 & 19,80 \\
K3 & & 16,00 & 22,30 & 15,00 & \\
K4 & 6,00 & 13,00 & 10,40 & 15,00 \\
K5 & 8,00 & 17,00 & 9,80 & 12,00 & 6,00 \\
\hline
\end{tabular}

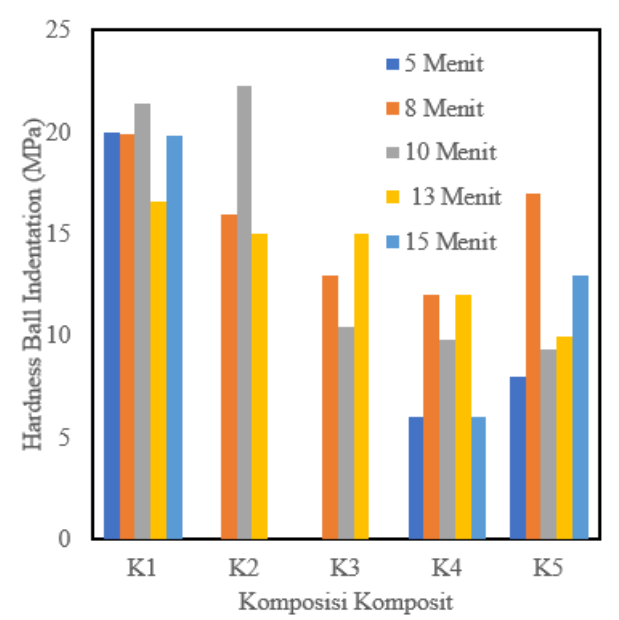

Gambar 4. Grafik Nilai Kekerasan Komposit EG-PVC-LDPE Terhadap Komposisi dan Waktu

Filler EG berfungsi sebagai reinforcement (penguat) yaitu penanggung beban utama untuk menahan sebagian besar gaya-gaya yang bekerja pada bahan komposit EG-PVC-LDPE, dengan matrik plastik LDPE-PVC melindungi dan mengikat filler agar dapat bekerja dengan baik. Pada Gambar 4, terlihat nilai kekerasan komposit EG-PVC-LDPE terhadap komposisi semakin turun dengan bertambahnya jumlah filler. Filler EG tidak dapat menahan gaya luar dikarenakan tidak kuat dan getas. Walaupun EG mempunyai serat-serat yang kaku dan kelangsingan (aspect ratio) yang tinggi. Namun perbandingan antara panjang dan diameter serat EG tidak cukup besar, sehingga tegangan geser yang terjadi pada permukaan antara filler dan matriks besar. Bahan matriks telah dipilih dari bahan yang liat dan lunak, agar mampu meneruskan tegangan geser. Namun demikian matriks plastik LDPE-PVC tidak dapat mengikat filler EG saat jumlah komposisi matriks dikurangi. Hal ini dapat dimengerti 
karena sekumpulan filler tanpa matriks tidak dapat menahan gaya dalam arah tekan dan transversal (Hado, Bambamng K).

Penurunan nilai kekerasan yang sangat signifikan terjadi pada komposisi Komposit 4 (K4) dimana nilainya sekitaran $6,00-12,00$ Mpa. Proses sintering dilakukan pada temperatur $180^{\circ} \mathrm{C}$, di bawah melting point $\mathrm{PVC}$ dan EG, saat diberi perlakuan siklus temal material LDPE mengalami perubahan fase dari padat ke fase cair. Perubahan fase mengakibatkan ikatan antar muka antara LDPE, PVC dan EG menjadi melemah dan lama kelamaan filler EG sudah mengisi penuh LDPE-PVC. Ikatan antar muka yang melemah akan menyebabkan kekerasan komposit EGPVC-LDPE berkurang. Nilai kekerasan berkurang karena penyatuian antar partikel yang kurang baik dan mengakibatkan masih banyaknya pori yang belum terisi. Pori-pori ini terbentuk dikarenakan kejenuhan filler EG dan ini merupakan tempat awal terjadinya retakan (initial crack).

Berdasarkan waktu terlihat bahwa hubungan antara komposisi komposit dan nilai kekerasan berubah-ubah. Ini dikarenakan bahan komposit termasuk kedalam kelompok bahan anisotropik, bahan yang sifat-sifatnya berubah dengan perubahan arah. Pada saat komposit disintering di temperatur $180^{\circ} \mathrm{C}$, rantai cabang LDPE-PVC tidak selamanya rantai lurus dan rapi, suatu ketika akan berbelok, melipat dan keluar dari barisan. Rantai yang keluar dari barisan dalam jumlah banyak kemudian mengelompok membentuk amrof (bentuk tak beraturan). Waktu tinggal adalah waktu yang diperlukan matriks dan filler saling berikatan, namun terlihat bahwa pengaruh waktu dan komposisi pada nilai kekerasan berubah-ubah dan tidak linear.

Nilai kekerasan tertinggi terlihat pada material Komposit K1 dan K2. Pada K1 nilai kekerasan antara 16,6 - 21,40 Mpa, sedangkan K2 nilai kekerasan antara $15,00-22,30 \mathrm{Mpa}$. Namun tetapi jika dilihat berdasarkan waktu, nilai kekerasan terlihat linear pada waktu 10 dan 13 menit. Jika melihat dari komposisi, jumlah filler EG yang tidak jauh signifikan dengan matriks LDPE-PVC berikatan secara kuat. Hal disebabkan oleh penyatuan antar partikel yang baik antara matrik dan filler, dan filler yang menjadi perekat sekaligus penanggung beban utama mengisi ronggarongga yang ada pada specimen. Hal ini juga terjadi pada penelitian Sunardi dkk (2015), yang melakukan penelitian tentang variasi campuran fly ash batu bara untuk material komposit. Bahwa semakin banyak komposisi serbuk fly ash maka nila kekerasan akan meningkat karena pada srbuk fly ash terdapat unsur kandungan logam yang dapat mempengaruhi kekerasan komposit. Dan jika melihat dari waktu, waktu tinggal selama 10 dan 13 menit lebih banyak terbentuk struktur kristalin. Pada proses kompaksi terjadi proses penarikan (stretching), pada saat tertarik maka struktur kristalin yang semula arahnya bervariasi menjadi lebih teratur menuju ke satu arah membentuk semacam serta. Komposit K2 dengan waktu tinggal 10 menit memiliki nilai kekerasan terbaik diantara komposisi dan waktu yang lain, yaitu 22,30 Mpa.

\subsection{Pengaruh Komposisi dan Waktu Terhadap Nilai Impak}

Berdasarkan pengujian Nilai Kekerasan didapatkan kekerasan terbaik ada pada waktu sintering 10 menit. Maka sebagai penguat sifat mekanik Komposit EG-PVC-LDPE ini, dilakukan pengujian impak untuk melihat nilai energi impak pada beban kejut yang dihasilkan. Pengujian impak dilakukan di Sentra Teknologi Polimer dengan menggunakan alat uji Resil Impactor CEAST dan menggunakan standar ISO 179. Menurut standar dimensi yang digunakan adalah: T: $4 \mathrm{~mm}$, L: $10 \mathrm{~mm}$ dan P: $80 \mathrm{~mm}$. Pengaruh waktu sintering terhadap kekuatan impak disajikan didalam Tabel 2 dan Gambar 5.

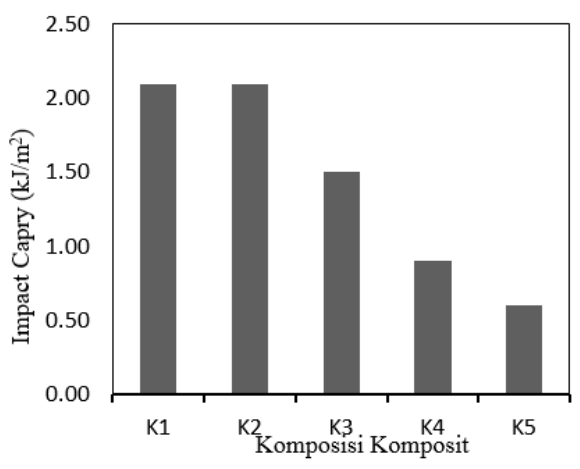

\section{Gambar 5. Grafik Nilai Impak Komposit EG-PVC-LDPE Terhadap Komposisi dan Waktu}

Pengaruh komposisi terhadap kekuatan impak pada masing-masing komposit terlihat cukup besar. Hal ini disebabkan karena filler EG merupakan penguat pada komposit dan berfungsi sebagai penanggung beban utama. Pengujian impak ini bertujuan untuk mengetahui ketangguhan suatu benda terhadap beban kejut, prinsip dari pengujian impak yaitu apabila benda diberi beban kejut, maka benda 
akan mengalami proses penyerapan energi sehingga terjadi deformasi elastis yang mengalami patah. Pengaruh komposisi terhadap waktu sintering pada nilai impak terlihat linear, dimana menunjukan semakin sedikit matriks dalam hal ini LDPE-PVC maka kekutan impak material komposit semakin menurun.

Tabel 1 Data Hasil Pengujian Impak Komposit EG-PVC-LDPE

\begin{tabular}{ccc}
\hline No. & $\begin{array}{c}\text { Nama } \\
\text { Sampel }\end{array}$ & $\begin{array}{c}\text { Impact Charpy } \\
\left(\mathbf{k J} / \mathbf{m}^{2}\right) \mathbf{1 0} \text { menit }\end{array}$ \\
\hline 1 & $\mathrm{~K} 1$ & 2,10 \\
2 & $\mathrm{~K} 2$ & 2,10 \\
3 & $\mathrm{~K} 3$ & 1,50 \\
4 & $\mathrm{~K} 4$ & 0,90 \\
5 & $\mathrm{~K} 5$ & 0,60 \\
\hline
\end{tabular}

Terlihat pada Tabel 2 Komposit K5 mempunyai nilai impak paling rendah yaitu 0,6 $\mathrm{kJ} / \mathrm{m}^{2}$, apabila dibandingkan dengan Komposit $\mathrm{K} 3$ dan $\mathrm{K} 4$ yaitu $1,5 \mathrm{~kJ} / \mathrm{m}^{2}$ dan $0,9 \mathrm{~kJ} / \mathrm{m}^{2}$, sedangkan Komposit K1 dan K2 menunjukan nilai impak tertinggi sebesar $2,1 \mathrm{~kJ} / \mathrm{m}^{2}$, energi yang diserap pada variasi komposisi yang banyak matriksnya akan berpengaruh pada nilai impaknya. Terbukti bahwa banyaknya matriks yang terkandung pada Komposit K1 dan K2 akan berperan sebagai pembentuk serat dan menghasilkan struktur bahan yang padat. Akan tetapi jika jumlah matriks berkurang, hasil tidak terlalu baik karena hasil menjadi lunak dengan diperkuat dari hasil nilai impak rendah.

Penurunan nilai material diakibatkan karena filler EG terlalu mendominasi sehingga membuat material komposit menjadi lebih lemah menahan beban yang diterima, dan tidak dapat berperan baik sebagai penanggung beban utama. Turunnya energi impak juga dikarenakan ikatan antara partikel pada EG dan LDPE-PVC belum berikatan dengan sempurna. Hal ini diperkuat oleh penelitian yang dilakukan Agung (2012), pengaruh waktu sintering terhadap komposit HDPE-sampah organic. Dimana Agung (2012) menyatakan bahwa penambahan waktu sintering akan menyebabkan serbuk HDPE bergerak untuk membentuk ikatan antar partikel, menyebabkan ikatan antar partikel dalam komposit menjadi lemah. Selain itu kemampuan HDPE untuk mengisi pori belum tampak, sehingga pori yang terjadi relatif jauh lebih besar dari pada variasi suhu sintering yang lain. Secara menyeluruh efek HDPE yang belum melunak juga dapat dikatakan sebagai penyebab buruknya sifat fisik maupun mekanik komposit.

Berdasarkan penelitian ini dapat dilihat bahwa banyaknya komposisi matriks LDPEPVC juga berbanding lurus antara nilai impak dengan nilai kekerasan komposit. Sehingga komposisi dan waktu pada material komposit berpengaruh terhadap sifat mekanik

\subsection{Pengaruh Komposisi dan Waktu Terhadap Morfologi BioKomposit \\ Pengujian SEM dilakukan di Sentra} Teknologi Polimer menggunakan alat uji JEOLJSM-6510LA dengan menggunakan dimensi T: $4 \mathrm{~mm}, \mathrm{~L}: 30 \mathrm{~mm}, \mathrm{P}: 30 \mathrm{~mm}$. Matriks LDPEPVC dan filler EG merupakan bahan komposit yang mengabungkan keunggulan kekuatan dan kekakuan filler dengan massa jenis matriks yang rendah. Penggabungan serat tidak dapat dilihat secara mata terbuka, diperlukan alat bantu SEM untuk melihat morfologi atau struktur komposit. Hasil foto SEM dapat terlihat pada Gambar 6 - 10 berikut:

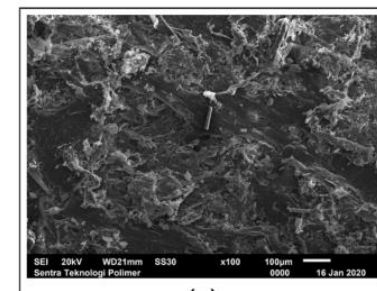

(a)

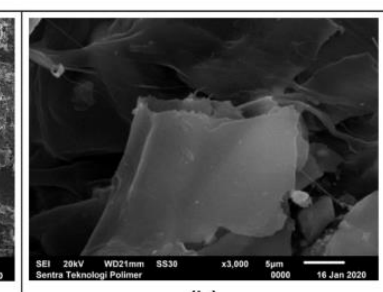

(b)
Gambar 6. Komposit K1 5 menit (a) SEM 100x; (b) SEM 3000x

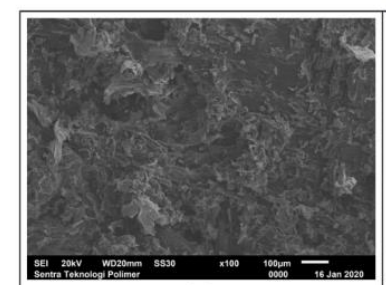

(a)

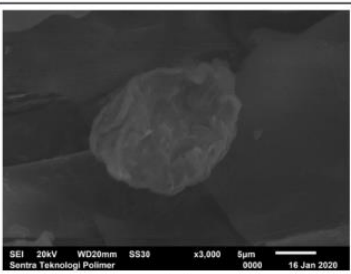

(b)
Gambar 7. Komposit K1 8 menit (a) SEM 100x; (b) SEM 3000x

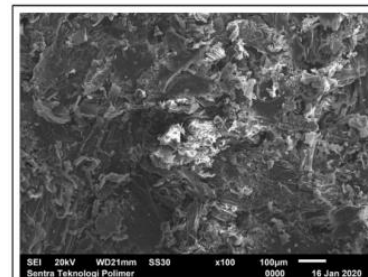

(a)

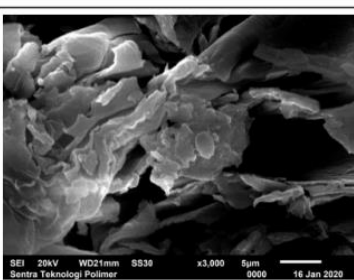

(b)
Gambar 8. Komposit K1 10 menit (a) SEM 100x; (b) SEM 3000x 


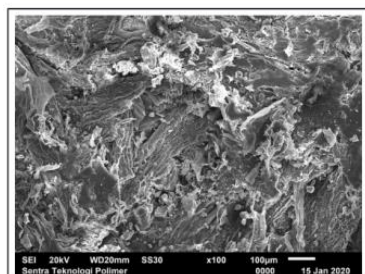

(a)

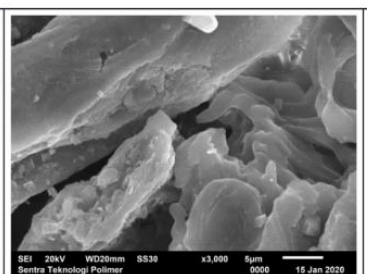

(b)
Gambar 9. Komposit K1 13 menit (a) SEM 100x; (b) SEM 3000x

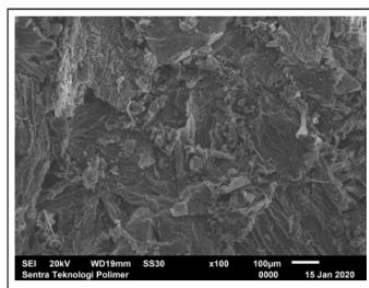

(a)

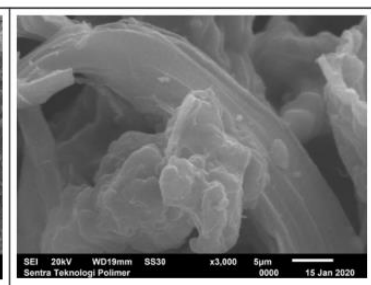

(b)
Gambar 10. Komposit K1 15 menit (a) SEM 100x; (b) SEM 3000x

Gambar 6 - 10 merupakan komposit K1 dengan variasi waktu tinggal sintering $5,8,10$, 13 dan 15 menit. Terlihat bahwa laminate (pelat berlapis) membangun struktur komposit, dimana beberapa partikel sudah menyatu antara fraksi volume matriks dan filler. Pencampuran matriks LDPE dan PVC ini dibuat agar elemen struktur mampu menahan beban multiaksial, sesuatu yang tidak dapat dicapai dengan lamina (lapisan tunggal). Matriks LDPE-PVC akan membentuk banyak serat dan saling berikatan dengan filler EG. Filler EG mengisi pori dan ruang kosong pada komposit. Jumlah rongga pada spesimen sedikit dan akan mengurangi peluang terjadinya getas pada spesimen. Karakteristik pori yang terjadi pada spesimen yaitu partikel LDPE dan PVC melunak dan mengikat serbuk EG cukup baik. Ini terbukti dari hasil nilai uji impak pada waktu 10 menit didapatkan nilai terbaik dari waktu yang lain yaitu sebesar $2.1 \mathrm{~kJ} / \mathrm{m}^{2}$. Berbanding lurus dengan nilai uji kekerasan yaitu $21.40 \mathrm{MPa}$, hal ini dikarenakan penyatuan ikatan antar partikel serbuk eceng gondok dengan LDPE-PVC menyatu dengan baik.

Hal yang sama terjadi pada Komposit K2, yang terlihat jelas pada Gambar 4.8 - 4.10. Pembentukan struktur kristalin matriks LDPEPVC 50-60\% dan karena jumlah kristalinitas rendah maka membuat komposit cenderung lentur. Kelenturan ini dapat dilihat dari nilai impak K2 pada waktu 10 menit adalah 2.1 $\mathrm{kJ} / \mathrm{m}^{2}$, dengan nilai kekerasan paling tinggi yaitu $22.30 \mathrm{MPa}$. Selain itu, pada bentuk struktur terlihat relatif transparan karena cukup banyak struktur amrofnya.

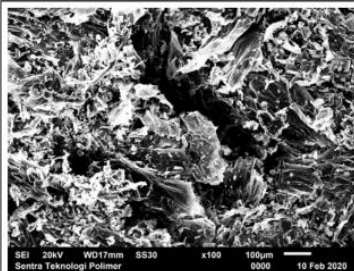

(a)

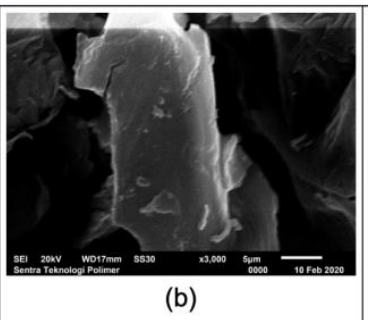

(b)
Gambar 11. Komposit K2 8 menit (a) SEM 100x; (b) SEM 3000x

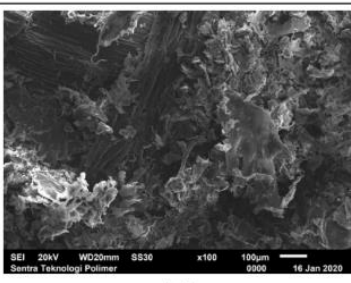

(a)

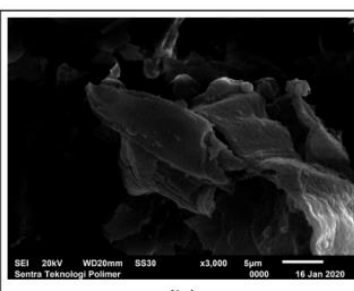

(b)
Gambar 12. Komposit K2 10 menit (a) SEM 100x; (b) SEM 3000x

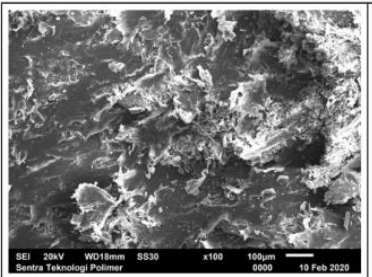

(a)

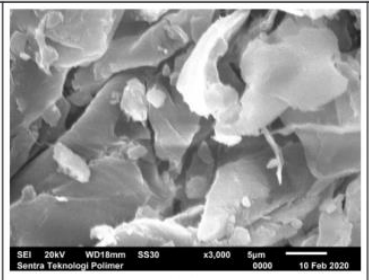

(b)
Gambar 13. Komposit K2 13 menit (a) SEM 100x; (b) SEM 3000x; (c) SEM 5000x

\section{KESIMPULAN}

Berdasarkan penelitian yang telah dilakukan, maka dapat diambil kesimpulan sebagai berikut:

1. Komposisi campuran Komposit Eceng Gondok-LDPE-PVC dan waktu sintering berpengaruh terhadap karakteristik mekanik kekerasan dan kekuatan impak. Didapatkan komposisi terbaik pada K2 dengan waktu 10 menit yaitu $22.30 \mathrm{MPa}$ untuk nilai kekerasan dan $2.1 \mathrm{~kJ} / \mathrm{m}^{2}$ untuk nilai impak

2. Pengaruh komposisi campuran Eceng Gondok-LDPE-PVC dan waktu sintering terhadap karakteristik morfologi material komposit terlihat pembetukan srtuktur kristal pada semua Komposit yang dihasilkan, perbedaan dapat dilihat dari jumlah matriks LDPE-PVC yang digunakan.

\section{DAFTAR PUSTAKA}

ASTM D-1037, Standard Test Methods for Evaluation Properties of Wood-Base Fiber and Particle Panel Materials. American 
Society for Testing and Material, USA, 1999.

ASTM D-5941, Standard Test Method for Determining the Izod Impact Strength of Plastics. American Society for Testing and Material, USA. 1996.

German, R.M., Powder Metallurgy Science, The Pensylvania State University, New Jersy. 1994.

Hameed, Awham Mohammed., Bilal, AbdulFatah Ahmed., Employment The Plastic Waste To Produce The Light Weight Concrete, Energy Procedia 157: International Conference on Technologies and Materials for Renewable Energy, Environment and Sustainability, TMREES18, pp. 30-38, Athens, Greece, September. 2018.

Hadi, Bambang Kismono., Mekanika Struktur Komposit, Modul Kuliah, Penerbit ITB, Bandung, 2012.

Indrayani, Novi Laura., Muhamad, Ramadhan., Netta, Lilliani., Studi Pengaruh Waktu Sintering Terhadap Sifat Kimia Dan Mekanik Komposit LDPE-PVC-SBR, Prosiding Seminar Nasional Energi dan Teknologi (SINERGI): Integrasi Teknologi Urban untuk Indonesia Cerdas, pp. 55-63, Bekasi, Juni. 2019.

Jiang, Shuaicheng., Yanqiang, Wei., Zhe, Hu., Shengbo, Ge., Hongqi, Yang., Wanxi, Peng., Sorini, Potential application of bamboo powder in PBS bamboo plastic composites, Journal of King Saud University - Scince, v. 32, pp. 1130-1134, 2020.

Karso, Triono., Wijang, Wisnu Raharjo., Heru, Sukanto., Pengaruh Variasi Suhu Siklus Termal Terhadap Karakteristik Mekanik Komposit HDPE-Sampah Organik, Jurnal Mekanika, v. 11, n. 1, pp. 8-13, September. 2012.

Rohmad, Agung., Heru, Sukanto., Wijang, Wisnu Raharjo., Karakterisasi Produk Ubin Berbahan Dasar Plastik PP dan Karet Ban Bekas dengan Metode Pressured Sintering, Jurnal Mekanika, v. 11, n. 2, pp. 123-129, Maret. 2013.

Seghiri, Mahdi., Djamel, Boutoutaou., Abdelouahed, Kriker., Mohamed, Ibrahim Hachani., The Possibility of Making a Composite Material from Waste Plastic, Energy Procedia 119: International Conference on Technologies and Materials for Renewable Energy, Environment and Sustainability, TMREES17, pp. 163-169,
Beirut Lebanon, April. 2017.

Setiajit, Sahid Bayu., Wijang, Wisnu Raharjo., Heru, Sukanto., Pengaruh waktu pengepresan terhadap sifat mekanik komposit kenaf/polypropylene, Jurnal Teknik Mesin Indonesia, v. 11, n. 2, pp. 8993, Oktober. 2016.

Sorini, Christopher., Aditi, Chattopadhyay., and Robert K, Goldberg., An Improved Plastically Dilatant Unified Viscoplastic Constitutive Formulation for Multiscale Analysis of Polymer Matrix Composites Under High Strain Rate Loading, Journal Composites Part B: Engineering, v. 184, 1 March 2020, link: https://doi.org/10.1016/j.compositesb.2019.1 07669. 